\title{
PREPARATION AND EVALUATION OF A NEW GASTRO-RETENTIVE EXTENDED RELEASE MECLOZINE HYDROCHLORIDE TABLETS
}

\author{
Abdullah M. Al-Mohizea \\ Department of Pharmaceutics, College of Pharmacy, King Saud University, Riyadh, Saudi \\ Arabia
}

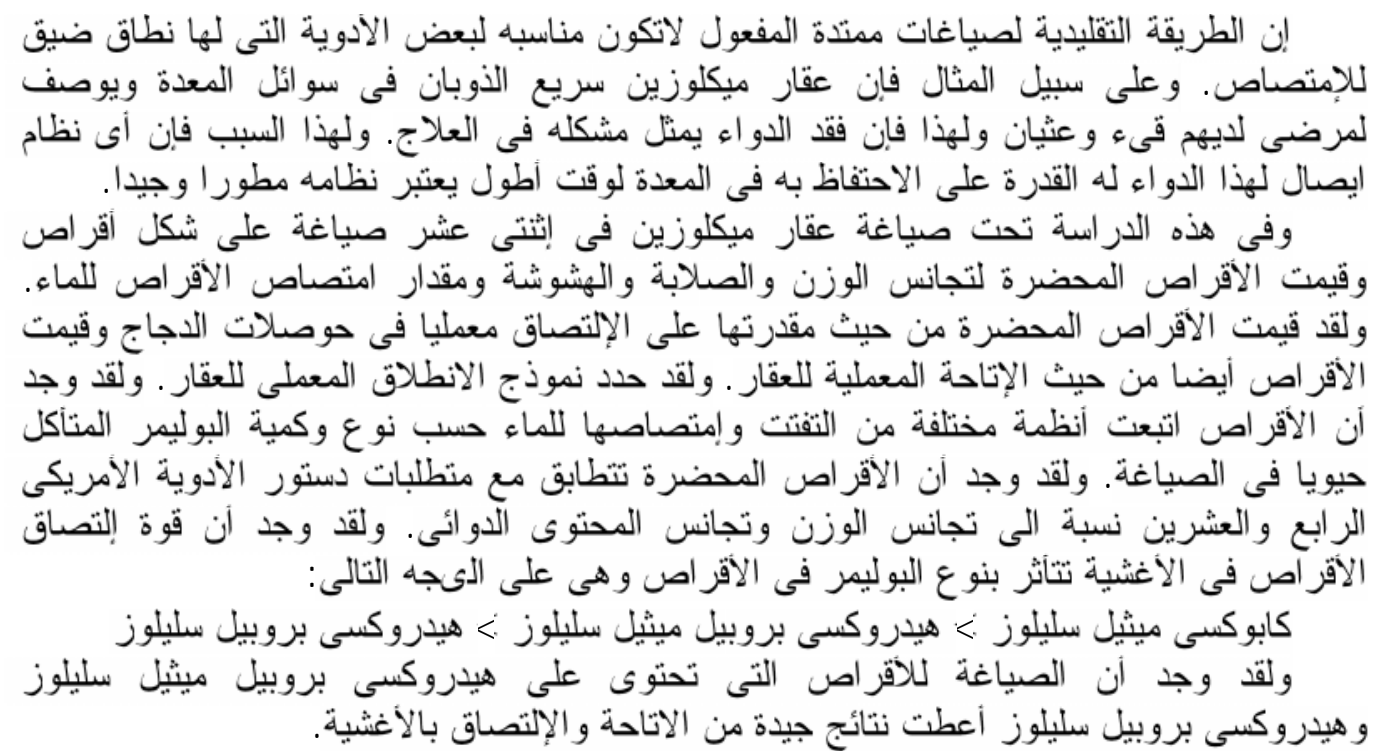

The conventional sustained release formulations are not suitable for drugs exhibiting a narrow window of absorption. For example, Meclozine, is highly soluble in only the gastric fluid and usually prescribed for patients who are experiencing nausea and vomiting and thus the risk of loosing the administered dose is always present. For this reason, any drug delivery system that is capable of keeping the drug in the stomach for a longer time will be advantageous. One approach to achieve this is the gastroretentive delivery systems. In this study, twelve formulae of Meclozine $\mathrm{HCl}$ tablets were prepared and evaluated for the uniformity of weight, hardness, friability, water uptake, and the percentage of increase in tablet weight. The in-vitro bioadhesion of the prepared formulae was evaluated using chicken pouches method. The in-vitro release studies of the prepared tablets were done and the percentage of drug released was calculated. Finally, the appropriate release model that describes the pattern of drug release was determined. The prepared tablets exhibited different disintegration and swelling profiles according to the type and amount of the bioadhesive polymer incorporated into the formula. All the prepared tablet formulae complied with the requirement of USP XXIV with regard to uniformity of weight and drug content. The mucoadhesive force of the investigated mucoadhesive polymers was found to be in the following order: $C M C>H P M C>$ $H P C>C P$. Formulae containing HPMC and HPC showed a promising in-vitro release and adhesion results.

\section{INTRODUCTION}

Meclozine is an $\mathrm{H}-1$ piperazine antihistamine derivative that possesses anticholinergic, antiemetic, antispasmodic, central nervous system depressant, and local anesthetic effects. Its antiemetic effects is due to suppression of the emetic center in the brain stem $^{1}$. Because it also reduces the excitability of neurons in the vestibular nucleus, it is often prescribed for motion sickness, vertigo, radiation dizziness, Meniere's disease, and 
nausea and vomiting during pregnancy. It is also used as antiemetic agent used in postoperative vomiting ${ }^{2}$.

The conventional sustained release formulations are not suitable if the drug exhibits a narrow window of absorption along the gastrointestinal tract. Meclozine, as an example, is highly soluble in the gastric fluid thus any drug delivery system that keeps the drug in the stomach will be advantageous for such drug. In addition, Meclozine is used with patients who are mostly experiencing nausea and vomiting and thus the risk of losing the dose administered is always present. For this reason, any drug delivery system that have adhesive properties to the stomach are also advantageous.

In recent years, many approaches have been developed in order to increase the gastric residence time of many drugs. One of these approaches is the gastroretentive delivery systems $^{3-5}$ which may be classified broadly into high-density or sinking systems, low-density or floating systems, expandable systems, superporous hydrogel systems, mucoadhesive systems and magnetic systems ${ }^{6}$.

The aim of this study is to design sustained release tablets using systems that have bioadhesive properties in order to keep the tablet of Meclozine in the stomach for the longest possible time and to prevent the tablet from being emptied when the patient vomit which is highly possible with such patients.

\section{MATERIALS AND METHODS}

\section{Materials}

Meclozine hydrochloride was kindly donated from Chemical Industries Development (CID) Co. (Cairo, Egypt). Carboxymethyl cellulose Sodium (CMC), high viscosity grade, and Sodium Sterile Fumarate (SSF) was purchased from BDH Co. (Poole, England). Hydrxypropyl methyl cellulose (HPMC K4M) was purchased from Dow Chemicals Co. (Michigan, USA). Carbopol 934P, was purchased from Sorgan Co. (Wiedelberg, Germany). Hydroxypropyl cellulose (HPC), average M.Wt 100,000, was purchased from Winlab Co. (UK). Microlac (a spray dried mixture of $75 \%$ lactose monohydrate and $25 \%$ microcrystalline cellulose), Starlac (a spray dried mixture of $85 \%$ lactose and $15 \%$ starch) were purchased from Molkerei Meggle Wasserburg Gmb and Co. (Germany).

\section{Methods}

\section{I- Preparation of Meclozine $\mathrm{HCl}$ matrix tablets}

Twelve formulae were prepared. Table 1 shows the exact composition of each formula. Powder blend equivalent to 50 tablets for each formula was weighed and mixed in a mortar then in a turbula mixer for 2 minutes. Tablets were prepared by weighing $203 \mathrm{mg}$ from the powder blend and was fed manually to the die and compressed under a constant compression conditions $(6 \mathrm{KN})$ using Erweka tabletting machine (EKO) fitted with $9 \mathrm{~mm}$ flat-faced punches.

Table 1: Composition of Meclozine $\mathrm{HCl}$ gastro retentive extended release tablets.

\begin{tabular}{|c|c|c|c|c|c|c|c|c|c|c|c|c|}
\hline \multirow{2}{*}{ Components (mg) } & \multicolumn{12}{|c|}{ Formula No. } \\
\hline & 1 & 2 & 3 & 4 & 5 & 6 & 7 & 8 & 9 & 10 & 11 & 12 \\
\hline Meclozine & 50 & 50 & 50 & 50 & 50 & 50 & 50 & 50 & 50 & 50 & 50 & 50 \\
\hline Starlac & 150 & -- & 100 & 100 & 100 & 100 & -- & -- & -- & -- & 100 & -- \\
\hline Microlac & -- & 150 & -- & -- & -- & -- & 100 & 100 & 100 & 100 & -- & 100 \\
\hline HPMC $^{\mathrm{a}}$ & -- & & 50 & & & & 50 & & & & 25 & 25 \\
\hline $\mathrm{CP}^{\mathrm{b}}$ & -- & -- & -- & 50 & -- & -- & -- & 50 & -- & -- & 25 & 25 \\
\hline $\mathrm{CMC}^{\mathrm{c}}$ & -- & -- & -- & -- & 50 & -- & -- & -- & 50 & & -- & -- \\
\hline $\mathrm{HPC}^{\mathrm{d}}$ & $\overline{--}$ & $\overline{--}$ & $\overline{--}$ & $\overline{--}$ & -- & 50 & $\overline{--}$ & $\overline{--}$ & $\overline{--}$ & 50 & $\overline{--}$ & -- \\
\hline $\mathrm{SSF}^{\mathrm{e}}$ & 3 & 3 & 3 & 3 & 3 & 3 & 3 & 3 & 3 & 3 & 3 & 3 \\
\hline $\begin{array}{c}\text { Average Tablet } \\
\text { Weight (mg) }\end{array}$ & 203 & 203 & 203 & 203 & 203 & 203 & 203 & 203 & 203 & 203 & 203 & 203 \\
\hline
\end{tabular}




\section{II- Evaluation of the prepared Meclozine HCl matrix tablets}

All the prepared tablet batches were evaluated for the uniformity of weight, hardness and friability according to the USP XXIX Specifications.

Measurement of water uptake of the prepared tablets: This test was done for 5 tablets from each formula. Each tablet was soaked in $50 \mathrm{ml}$ of $0.1 \mathrm{~N} \mathrm{HCl}$ solution $\left(37^{\circ} \mathrm{C} \pm\right.$ $5^{\circ} \mathrm{C}$ ) for 30 minutes. The tablet was then removed, the excess media on its surface was carefully dried using a filter paper, and the percent increase in the weight of the tablet was calculated. This percentage was taken as a measure of water uptake (hydration):

$$
\% \text { hydration }=(\mathrm{Wz}-\mathrm{Wi}) / \mathrm{Wi}) \times 100
$$

Where; Wi is the initial tablet weight and $\mathrm{Wz}$ is the final tablet weight at time $t$.

In-vitro bioadhesion test of the prepared tablets: in-vitro bioadhesion of the prepared formulae was evaluated using a previously published method ${ }^{7}$. In this method, chicken pouches are used as a model of mucosal membrane. After slaughtering the chicken, the pouches are cleaned from its contents and the surrounding fat and then freeze stored in normal saline solution. Before use, each pouch was thawed at room temperature and cut into rectangular pieces (surface area $=2 \mathrm{~cm}^{2}$ ) and then was glued on the ground surface of the upper tissue holder (made of Plexiglas) with cyanoacrylate adhesive. The tablet was fixed to the lower holder. Twenty microletter of $0.1 \mathrm{~N}$ $\mathrm{HCl}$ was placed on the surface of the tablet and then the two surfaces were put in contact with uniform and constant light pressure by fingers for one minute in order to facilitate the adhesion bonding. The upper holder was hanged on an iron stand with the aid of an aluminum wire fastened with a hook. A pre weighed light weight polyethylene bag was attached to the hook on the back side of the lower tissue holder with aluminum wire. After one minute of pre-loading time, water was added to the polyethylene bag using an intravenous infusion set at a rate of 2 drops per second until detachment of the lower tissue occurs as a result of the heavy weight of water.
The water inside the polyethylene bag was measured and expressed as the weight required for the detachment. Figure 1 shows the diagram of the apparatus used ${ }^{7}$.

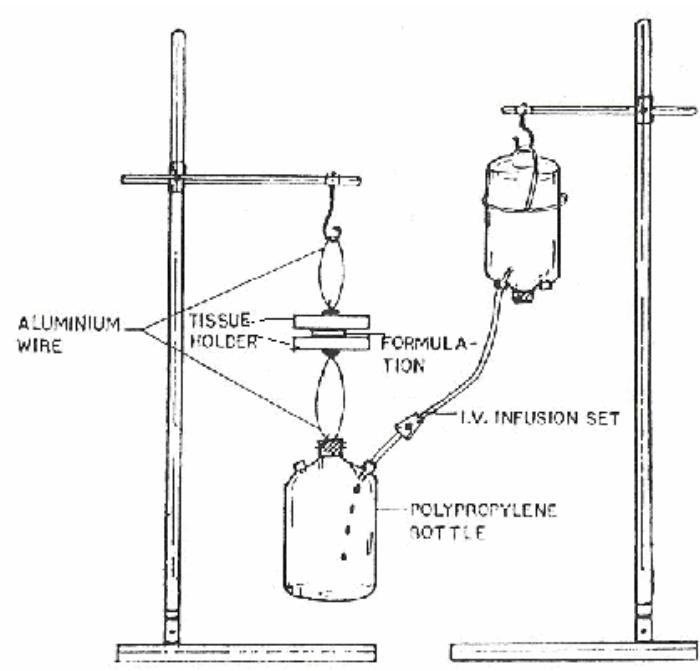

Fig. 1: Modified apparatus for in-vitro bioadhesion test (adapted from reference 7).

There are several studies using different techniques to measure the mucoadhesive force between the dosage form and the mucosal membrane. In this study, the bioadhesive force expressed as the detachment stress in dyne $/ \mathrm{cm}^{2}$ was determined from the minimal weights loaded that detached the mucosal surface from the tablet using the following equation:

$$
\text { Detachment stress }\left(\text { dyne } / \mathrm{cm}^{2}\right)=\mathrm{m} \cdot \mathrm{g} / \mathrm{A}
$$

Where $m$ is the weight of water infused at detachment, $\mathrm{g}$ is the acceleration due to gravity considered as $980 \mathrm{~cm} / \mathrm{S}^{2}$, and $\mathrm{A}$ is the exposed surface area of tissue $\left(\mathrm{cm}^{2}\right)$.

In-vitro release studies of the prepared Meclozine HCl tablets: the dissolution test was performed using standard USP apparatus No. 2 (Paddle) at $50 \mathrm{rpm}$. The dissolution medium was 0.9 liter of $0.1 \mathrm{~N} \mathrm{HCl}$. The drug release was monitored using a continuous automated monitoring system which consists of a Watson-Marlow peristaltic pump, Philips Vis/UV/NIR spectrophotometer and PH8605160 dissolution software. Test was run in triplicate, absorbance at $233 \mathrm{~nm}$ was recorded automatically up to $8 \mathrm{hrs}$ and the percentage of drug release was calculated. 
Kinetic assessment of the in-vitro release data

In order to determine the appropriate release model that describes the pattern of drug release, the release data were fitted according to zero order, first order $^{8}$ and diffusion controlled release models-the simplified Higuchi model $^{9}$ according the following equations:

Zero-order kinetic model:

$$
\left.\mathrm{C}=\mathrm{C}_{\mathrm{o}}-\mathrm{K}_{\mathrm{o}} \mathrm{t} \ldots \ldots \ldots \ldots \ldots \ldots \ldots \ldots \text { (equation } 1\right)
$$

First-order kinetic model:

$$
\log \mathrm{C}=\log \mathrm{C}_{\mathrm{o}}-\mathrm{kt} / 2.203 \ldots . . \text { (equation 2) }
$$

Higuchi simplified diffusion model:

$$
\mathrm{Q}=2 \operatorname{Co}(\mathrm{Dt} / \pi)^{1 / 2}
$$

Where, Co is the initial drug concentration, C is the drug concentration remaining at time $\mathrm{t}, \mathrm{t}$ is the time of sampling, $\mathrm{Q}$ is the amount of drug released per unit area, $\mathrm{K}_{\mathrm{o}}$ is the zero-order rate constant and $\mathrm{D}$ is the diffusion coefficient that was calculated according to the following equation:

$$
\mathrm{D}=(\text { slope } / 2 \mathrm{Co})^{2} \pi .
$$
(equation 4)

The appropriateness of a certain model was based on the correlation coefficient (r) for the studied parameters. The higher the correlation coefficient the more appropriate is the selected mode $1^{10}$. Further evidence for the relative validity of the first order and diffusion models was achieved by using the following equation $^{11}$ :

$$
\mathrm{M}_{\mathrm{t}} / \mathrm{M}_{\infty}=\mathrm{K} \mathrm{t}^{\mathrm{n}}
$$

(equation 5)

Where $\mathrm{Mt} / \mathrm{M} \infty$ is the fraction of drug released at time $t, K$ is a constant that incorporates structural and geometrical characteristics and $\mathrm{n}$ is the release exponent characteristic for the drug transport mechanism. When $n=0.5$, fickian diffusion is observerd and the release rate is dependent on $\mathrm{t}$, whereas $0.5<\mathrm{n}<1.0$ indicate anomalous (non fickian) transport and when $\mathrm{n}=1$, the release is zero-order.

\section{Statistical analysis}

One way ANOVA followed by Tukey test was done to evaluate the presence of significant differences between different formulas at a $p$-value $\leq 0.05$. This was carried out using Prism Software version 3.02 (GraphPad Software Inc., San Diego, CA).

\section{RESULTS AND DISCUSSION}

\section{Physicochemical properties of the prepared tablets}

All the prepared tablet formulae complied with the requirement of USP XXIV with regard to uniformity of weight and drug content. The hardness values for all the prepared formulae were in the acceptable range (6-9 kp) and the \% friability for all the formulae was also acceptable $(<1 \%)$ (Table 2). This reflects a good mechanical properties of the prepared tablet formulations.

Table 2: Physiomechanical Evaluation of Meclozine $\mathrm{HCl}$ gastro retentive extended release prepared tablets.

\begin{tabular}{|c|c|c|c|c|c|c|c|c|c|c|c|c|}
\hline \multirow{2}{*}{ Parameters } & \multicolumn{10}{|c|}{ Formula No. } \\
\cline { 2 - 19 } & $\mathbf{1}$ & $\mathbf{2}$ & $\mathbf{3}$ & $\mathbf{4}$ & $\mathbf{5}$ & $\mathbf{6}$ & $\mathbf{7}$ & $\mathbf{8}$ & $\mathbf{9}$ & $\mathbf{1 0}$ & $\mathbf{1 1}$ & $\mathbf{1 2}$ \\
\hline $\begin{array}{c}\text { Average } \\
\text { tablet weight } \\
(\mathrm{mg}) \pm \text { STD }\end{array}$ & $204 \pm 1.5$ & $203 \pm 2.0$ & $204 \pm 1.2$ & $203 \pm 1.1$ & $205 \pm 2.0$ & $204 \pm 1.1$ & $203 \pm 1.3$ & $204 \pm 1.1$ & $204 \pm 1.0$ & $205 \pm 1.2$ & $204 \pm 1.5$ & $203 \pm 1.2$ \\
\hline $\begin{array}{c}\text { Hardness } \\
(\mathrm{Kp})\end{array}$ & $6.0 \pm 0.5$ & $6.1 \pm 0.6$ & $6.25 \pm 0.5$ & $9.2 \pm 0.7$ & $7.0 \pm 0.6$ & $7.1 \pm 0.8$ & $6.5 \pm 0.4$ & $9.4 \pm 0.6$ & $6.8 \pm 0.4$ & $6.9 \pm 0.5$ & $8.5 \pm 0.6$ & $8.6 \pm 0.5$ \\
\hline$\%$ Friability & 0.50 & 0.60 & 0.40 & 0.30 & 0.60 & 0.51 & 0.41 & 0.28 & 0.58 & 0.60 & 0.25 & 0.26 \\
\hline
\end{tabular}




\section{Swelling behavior and disintegration characteristics}

Table 3 shows that the prepared tablets exhibited different disintegration and swelling profile according to the type and amount of the bioadhesive polymer incorporated into the formula. All the formulae containing HPMC showed no disintegration and high swelling values. The highest swelling was observed with formulations containing CMC. After $30 \mathrm{~min}$ in Simulated Gastric Fluid (SGF), the prepared tablets swelled in the following order, namely: $\mathrm{CMC}>\mathrm{HPMC}>\mathrm{HPC}>\mathrm{CP}$. Formulations containing no bioadhesive polymers showed rapid disintegration without swelling. Formulations containing CP (formula $4 \& 8$ ) showed also rapid disintegration. This could be attributed to the acidic $\mathrm{pH}$ of the medium, thus $\mathrm{CP}$ will be in the unionized form. Dissociation and ionization of $\mathrm{CP}$ is essential for its swelling ${ }^{12}$. Changing the diluents (Starlac or Microlac) did not affect the swelling behavior of the polymers and consequently the tablet.

The swelling behavior of the polymer was reported to be crucial for its bioadhesive behavior ${ }^{12 \& 13}$. The adhesion occurs rapidly after the beginning of swelling. The adhesion was increased with the degree of hydration until a point where over hydration leads to an abrupt drop in adhesive strength due to disentanglement at the polymer tissue interface and disintegration. Thus, the extent of tablet hydration and swelling will also affect the drug release from the tablet.

\section{In-vitro bioadhesion of the prepared tablets}

There are several advantages in having bioadhesive drug delivery systems. As a result of such adhesion, the formulation stays longer time at the delivery site and this improves the bioavailability of the drug. So, the bioadhesive force is an important physiochemical parameter for gastro-retentive tablets. Adhesion occurs rapidly after the beginning of hydration and swelling of the tablets. Various mechanisms have been proposed to explain the in-vitro bioadhesion phenomena. These include hydrogen bonding, Van der Waals forces, hydrophobic bonding, wetting, and surface force energy ${ }^{12}$.

Table 4 shows the results of bioadhesion test of the prepared tablets. From the results obtained, it could be concluded that the mucoadhesive polymers investigated could be arranged according to their mucoadhesive force as follows: $\mathrm{CMC}>\mathrm{HPMC}>\mathrm{HPC}>\mathrm{CP}$. This is in accordance with swelling state data. The combination of CP with HPMC gave acceptable adhesion and swelling behavior in the formulated tablets.

Table 3: Swelling behavior of Meclozine gastroretentive extended release tablets at $30 \mathrm{~min}$.

\begin{tabular}{|c|c|c|c|c|}
\hline $\begin{array}{c}\text { Formula } \\
\#\end{array}$ & $\begin{array}{c}\text { Weight at } \\
\text { zero time }\end{array}$ & $\begin{array}{c}\text { Weight at } \\
30 \mathrm{~min}\end{array}$ & $\begin{array}{c}\% \\
\text { Hydration }\end{array}$ & $\begin{array}{c}\text { Disintegration } \\
\text { time (min) }\end{array}$ \\
\hline 1 & 202 & $\mathrm{D}$ & - & 23 \\
\hline 2 & 201 & $\mathrm{D}$ & - & 26 \\
\hline 3 & 200 & 430 & 115 & - \\
\hline 4 & 201 & $\mathrm{D}$ & - & 20 \\
\hline 5 & 199 & 510 & 155 & 120 \\
\hline 6 & 202 & 350 & 75 & 360 \\
\hline 7 & 199 & 450 & 125 & - \\
\hline 8 & 198 & $\mathrm{D}$ & - & 22 \\
\hline 9 & 200 & 490 & 145 & 420 \\
\hline 10 & 202 & 360 & 80 & 600 \\
\hline 11 & 203 & 340 & 70 & - \\
\hline 12 & 202 & 350 & 75 & - \\
\hline
\end{tabular}

$\mathrm{D}=$ The tablet disintegrated 
Table 4: Bioadhesive force of Meclozine $\mathrm{HCl}$ gastro retentive extended release prepared tablets.

\begin{tabular}{|c|c|c|}
\hline Formula No. & $\begin{array}{c}\text { Bioadhesive force } \\
\left(\text { Dyne/cm } \mathrm{cm}^{2} 0^{-3}\right)\end{array}$ & $\mathrm{pH}$ \\
\hline 1 & No adhesion & 5.0 \\
\hline 2 & No adhesion & 5.0 \\
\hline 3 & 42.50 & 5.1 \\
\hline 4 & 27.71 & 4.1 \\
\hline 5 & 47.30 & 5.3 \\
\hline 6 & 32.60 & 5.2 \\
\hline 7 & 42.40 & 5.0 \\
\hline 8 & 25.60 & 4.0 \\
\hline 9 & 48.00 & 5.5 \\
\hline 10 & 34.20 & 5.1 \\
\hline 11 & 35.60 & 4.5 \\
\hline 12 & 36.00 & 4.5 \\
\hline \multicolumn{2}{|l}{} \\
\hline
\end{tabular}

\section{In-vitro release studies of Meclozine $\mathrm{HCl}$ from the prepared tablets}

Figure 2 shows the release profiles of Meclozine $\mathrm{HCl}$ form the prepared tablets. It is clear that the drug is rapidly released from the formulation that contains no bioadhesive polymer (the release is significantly different from the formulations containing bioadhesive polymers). In the mean time, some polymers (CP and $\mathrm{CMC}$ ) failed to sustain the release of the drug. This failure may be due to the acidic $\mathrm{pH}$ of the medium used ( $\mathrm{pH}$ 1.2). At this $\mathrm{pH}$, both $\mathrm{CP}$ and $\mathrm{CMC}$ are mainly unionized. Ionization is essential for these polymers to form adequate swelled matrix and sustain the release $^{13 \& 14}$. On the other hand, HPMC and HPC (neutral non ionized polymers) succeeded in sustaining the drug release with varying degrees. As it was reported, the higher viscosity grade of HPMC acts through its swelling characteristics or through increasing the viscosity depending on the diluent used ${ }^{14}$. In this study, the diluents, microlac, showed more retardation to the drug release in comparison to starlac for both polymers (HPMC \& HPC). Addition of CP to HPMC (F11 \& F12) results in more sustaining of the drug release. This probably due to less swelling behavior of these formulations.

In conclusion, formulae made with HPMC and HPC (F3, F7, F6 and F10) showed a promising in-vitro release and adhesion results.

\section{Study of release kinetics for $\mathrm{Meclozine} \mathbf{H C l}$ from these formulations}

In swellable systems, factors affecting the release kinetics are liquid diffusion rate and polymeric chain relaxation rate. When the liquid diffusion is slower than the relaxation rate of the polymeric chains, the diffusion is Fickian, whereas when the relaxation process is very slow as compared with the diffusion rate, the case II transport occurs.

When liquid diffusion rate and polymer relaxation rate are of the same order of magnitude, anomalous or non-Fickian diffusion is observed ${ }^{15}$.

Table 5 presents the results of kinetic modeling for the prepared Formulae F3, F7, F6 and F10. F3 and F7 containing starlc show a non-Fickian release behavior of Meclozine $\mathrm{HCl}$, however formula F6 and F10 containing microlac nearly approached zero order (case II transport) release. 


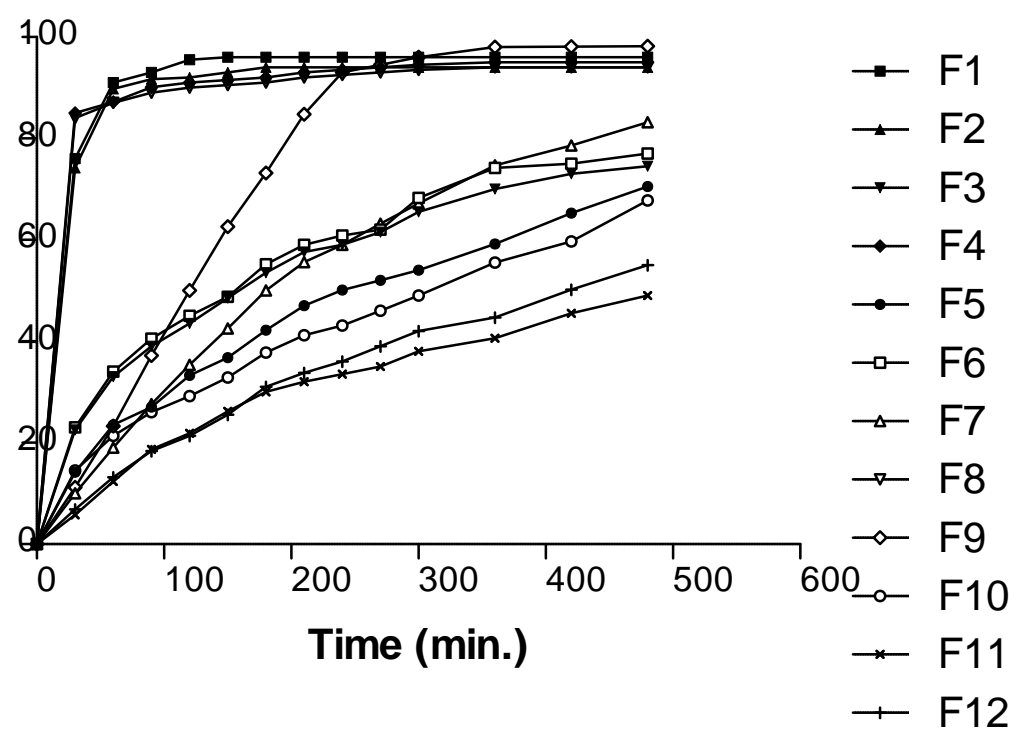

Fig. 2: In-vitro release profile of Meclozine from its prepared tablets.

Table 5: Values of regression coefficients (r) and release exponents from release data of the formulae showing sustained release properties.

\begin{tabular}{||c|c|c|c|c|}
\hline \hline Model & \multicolumn{4}{|c|}{ Formula No. } \\
\hline & F3 & F7 & F6 & F10 \\
\hline Zero order & 0.916611 & 0.967264 & 0.918846 & 0.974172 \\
\hline First order & -0.97894 & -0.99955 & -0.9804 & -0.99296 \\
\hline Higuhi & 0.992391 & 0.989908 & 0.992162 & 0.996368 \\
\hline n values & 0.9792 & 0.997556 & 0.979182 & 0.994605 \\
\hline
\end{tabular}

\section{Conclusion}

In conclusion, all the prepared tablet formulae complied with the requirement of USP XXIV with regard to friability, uniformity of weight and drug content. Formulae made with HPMC and HPC (F3, F7, F6 and F10) showed a promising in-vitro release and adhesion results. This will prolong the release of Meclozine in the stomach, enhance its absorption and prevent the dose to be emptied when the patient vomit which is highly possible with such patients.

\section{Acknowledgment}

The Author is grateful to the Research Center, College of Pharmacy, King Saud University, for the financial support of this project.

\section{REFERENCES}

1- C. D. Wood, D. B. Cramer and A. Graybiel, Otol. Head Neck Surg., 89, 1041 (1981).

2- N. T. Abdel-Ghani, A. F. Shoukry, Y. M. Issa and O. A. Wahdan, J. Pharm. Biomed. Anal., 28, 373 (2001).

3- A. A. Deshpande, N. H. Shah, C. T. Rhodes and W. Malick, Drug Dev. Ind. Pharm., 22, 531 (1996).

4- B. N. Singh and H. N. Kim, J. Control Release, 63, 235 (2000).

5- C. Sauzet, M. Claeys-Brunob, M. Nicolasc, P. Kister Piccerelle and P. Prinderrea, Int. J. Pharmaceutics, 378, 23 (2009). 
6- P. L. Bardonnet, V. Faivre, W. J. Pugh, J. C. Piffaretti and F. Falson, J. Control Release, 111, 1 (2006).

7- V. Agarwal and B. Mishra, Drug Dev. Ind. Pharm., 25, 701 (1999).

8- A. Martin, "Physical Pharmacy", $4^{\text {th }}$ Ed., Lea and Febiger, U.S.A., 1993, pp. 497, 286, 287, 361.

9- W. I. Higuhci, J. Pharm. Sci., 51, 802 (1962).

10- Y. Samuelov, M. Donbrow and M. Friedman, ibid., 68, 325 (1979).

11- N. A. Peppas, Pharm. Acta. Helv., 60, 110 (1985).
12- J. L. Chen and G. N. Cyr, "Compositions Producing Adhesion Through Hydration, Adhesion in Biological Systems", R. S. Manly Ed., Academic Press, London, 1970, p. 163.

13- I. G. Needleman, G. P. Martin and F. C. Smales, J. Clin. Periodontal., 25, 74 (1998).

14- G. M. Khan and Z. J. Jiabi, Controlled Release., 54, 185 (1998).

15- R. W. Korsmeyer and N. A. Peppas, "Controlled Release Delivery Systems", In: T. J. Roseman and S. Z. Mansdorf, M. Dekker, New York, 1983, pp. 77-90. 